\title{
Removal of Cationic Neutral Red Dye from Aqueous Solutions Using Natural and Modified Rice Straw
}

\author{
R.M.M. Aboelenin ${ }^{1 *}$, S.A. Kheder ${ }^{1}$, H.K. Farag ${ }^{2}$ and Th. El Nabarawy ${ }^{1}$ \\ ${ }^{1}$ Physical Chemistry Department, and ${ }^{2}$ Inorganic Chemistry Department, National \\ Research Centre, 33 El-Behouth St. , Dokki, Giza, Egypt
}

\begin{abstract}
$\mathbf{M}$ ODIFIED colloidal carbons were prepared by reacting colloidal carbon obtained from rice straw with thermal oxidation, nitric acid and urea treatment. The textural and chemistry characteristics of the surface of non-modified and modified carbons were obtained from nitrogen adsorption at $-196^{\circ} \mathrm{C}$, elemental analysis and fourier transform infrared (FTIR) techniques. The uptake of cationic neutral red (NR) dye from aqueous solutions by these carbons was determined by kinetic and equilibrium experiments. The surface area and the total pore volume decreased, whereas the pore radius increased after the treatment with nitric acid. The surface $\mathrm{pH}$ of un-modified carbon was basic while those of modified carbons were acidic. Urea treated carbons with the lowest acidic character and high nitrogen content presented the lowest NR dye uptake capacity. The maximum removal of NR dye was obtained at a $\mathrm{pH}$ of 4 . The amount of adsorption by the investigated carbons was found to depend on the amount of surface acidity. The adsorption results were analyzed considering Langmuir, Freundlich and Dubinin-Radushkevich(D-R) models. The adsorption of NR dye onto the assessed adsorbents is of the physical sorption type following pseudo - first - order kinetic.Nitric acid modification brought about a significant rise in NR dye adsorption which was ascribed to the formation of oxygen containing acidic groups on the surface of adsorbent. The equilibrium adsorption data of NR dye were well fitted with Langmuir and D-R models.
\end{abstract}

Keywords: Rice straw,Colloidal carbon, Adsorption, Neutral red dye,Surface chemistry

\section{INTRODUCTION}

The properties of carbon materials as adsorbents are strongly dependent on the textural features and on the chemical surface functionalities [14]. The textural characteristics are described by the porosity and surface area while the surface functionalities are mainly composed of surface oxygen containing groups classified as acidic, basic and neutral groups [3,4]. The surface functional groups are capable to play an important role in the adsorption performance of carbons as these groups in pore entrances can influence not only the access of adsorbents but also the selective adsorption of individual species [5-8].

Surface functional groups responsible for the carbon characteristics comprise carbonyl, carboxyl, phenol, quinone, lactone and others bound to edges of the graphite-like layers $[9,10]$. The nature and concentration of these groups might be modified by different oxidizing agent treatment methods [11-14].Thermal treatment is used for dry oxidation and concentrated nitric acid and concentrated urea are applied in wet oxidation. Oxidation may also influence the pore structure development. Alternatively, other modification processes were described, such as urea, ammonia and other nitrogen containing substances $[12,13]$.

Activated carbons are generally employed for the removal of dyes from water and wastewater owing to their high sorption capability for inorganic and organic pollutants. Adsorption has proved to be one of the most effective physicochemical methods for textile wastewater treatment. Extensive studies were performed to improve the sorption capacities of activated carbon prepared from agricultural by-products for dye removal but relatively less work is reported to physical or chemical modified carbons $[14,15]$. 
The aim of this work was to modify colloidal carbon prepared from rice straw with sulphuric acid using dry modified (thermally treated at $600{ }^{\circ} \mathrm{C}$ for $4 \mathrm{hr}$ ) and wet modified treatment with either concentrated nitric acid or saturated urea solution then thermally treated at $600^{\circ} \mathrm{C}$ to enhance the weakly acidic functional groups and the surface nitrogen groups respectively. Such modifications can improve the adsorption capacity of the colloidal carbon. The adsorption of cationic dye, neutral red (NR), on the modified colloidal carbon was investigated. The study also comprises characterization of the adsorbents and the determination of the factors influencing the sorption, including the contact time, $\mathrm{pH}$ and temperature.

\section{Experimental}

\section{Materials and methods}

\section{Adsorbent preparation}

Rice straw was collected and washed several times to ensure the removal of dust and ash. It was subsequently rinsed several times with distilled water and dried in hot air-oven at $50{ }^{\circ} \mathrm{C}$ overnight. The dried rice straw was ground to pass through a $1 \mathrm{~mm}$ sieve and designated as sample RS sample. Colloidal carbon was obtained by reacting $10 \mathrm{~g}$ of RS with $100 \mathrm{ml}(12 \mathrm{~mol} / \mathrm{L})$ sulphuric acid at $30^{\circ} \mathrm{C}$ for $24 \mathrm{hr}$. The resulting black mixture was allowed to cool and then filtered using a Buchner funnel. The carbonized product was washed several times with distilled water until the $\mathrm{pH}$ neutral $(\mathrm{pH}=7)$ which did not give a precipitate with barium chloride solution. The product known as colloidal carbon was denoted as (C).

To prepared modified colloidal carbons, three alternative treatment steps were applied to colloidal carbon surface which included:

(a) Thermal partial oxidation by air.

(b) Liquid phase oxidation by conc.Nitricacid solution.

(c) Thermal treatment of urea treatment carbon sample.

Thermal oxidation of colloidal carbon (C) obtained was carried out in a fixed bed reactor at $600^{\circ} \mathrm{C}$ for $4 \mathrm{hr}$ to generate C-Th. Liquid phase oxidation took place by oxidizing (C) with $30 \% \mathrm{~V} / \mathrm{V}$ concentrated nitric acid at room temperature for $48 \mathrm{hr}$. The ratio of carbon to acid was 1:3 (V/V). Humic compounds formed were leached out of the carbon by washing with distilled water until the $\mathrm{pH}$ reached neutral and finally rinsed with double distilled water and then the carbon sample was dried overnight at $110^{\circ} \mathrm{C}$ prior to being used. $\mathrm{HNO}_{3}$ - oxidized carbon was designating as $\mathrm{C}-\mathrm{N}$. The urea impregnation procedure included the addition of about $5 \mathrm{~g}$ of $\mathrm{C}$ in a glass beaker containing $150 \mathrm{ml}$ of saturated urea solution. The mixture was stirred for $1 \mathrm{~h}$ at $30{ }^{\circ} \mathrm{C}$. The treated sample was then filtered off, washed by distilled water to remove any excess of urea and dried at $100^{\circ} \mathrm{C}$. The heat treatment was carried out in the fixed bed reactor at $450^{\circ} \mathrm{C}$ for 1 h. Urea treated colloidal carbon was labelled as C-u.

\section{Neutral Red Dye (NR)}

A basic dye was used in experiments as an adsorbate which is widely used in the textile industry ; its molecular formula is written as 3-amino-7-dimethyl amino -2-methyl phenazine with molecular weight of $288.78 \mathrm{~g} / \mathrm{mol}$, the corresponding structure is illustrated in Scheme 1.<smiles>Cc1cc2nc3ccc(N(C)C)cc3nc2cc1N</smiles>

Scheme 1: Chemical structure of cationic Neutral Red dye (NR)

\section{Techniques \\ Instruments used for adsorbent characterization}

The textural parameter, such as the BETsurface area $\left(\mathrm{S}_{\mathrm{BET}}, \mathrm{m}^{2} / \mathrm{g}\right)$, total pore volume $\left(\mathrm{V}_{\mathrm{T}}\right)$ and average pore diameter $(\mathrm{r})$ were evaluated from BET- equation using Quantachrome Nova Automated $\mathrm{N}_{2}$ gas adsorption at $-196{ }^{\circ} \mathrm{C}$. In addition, an estimate for micropore $\left(\mathrm{V}_{\text {micro }}, \mathrm{ml} / \mathrm{g}\right)$ and non-micropore $\left(\mathrm{V}_{\text {non-micro }}, \mathrm{ml} / \mathrm{g}\right)$ volumes using the t-plot method was obtained [16].

For the chemical characterization of prepared carbons, $\mathrm{CHN}$ analysis was performed. The carbon, hydrogen, and nitrogen contents of the three samples were determined automatically by a VARIO Microanalyzer System.The different types of functional groups were identified by fourier transform infrared (FT-IR) spectroscopy in the range of $4000-400 \mathrm{~cm}^{-1}$ using a Perkin Elmer Paragon 1000 FT-IR Spectrometer (USA), and the $\mathrm{KBr}$ disc technique. 
The chemistry of the surface as determined from the surface $\mathrm{pH}$ and the relative concentrations of different surface functional groups in investigated carbons were determined according to the Boehm's titration method [12$15,17]$.The surface $\mathrm{pH}$ values were measured in a suspension of $1 \mathrm{~g}$ of carbon $20 \mathrm{ml}$ of $\mathrm{CO}_{2}$ - free distilled water after a contact time of $48 \mathrm{hr}$ at 25 ${ }^{\circ} \mathrm{C}$. The $\mathrm{pH}-$ meter used was of digital type (Pope Model No. 1501).

The kinetic experiments of neutral red (NR) dye sorption were carried out using all investigated carbons at $30^{\circ} \mathrm{C}$ and $\mathrm{pH}=4$. A 250 $\mathrm{ml}$ of $200 \mathrm{ppm}$ dye solution was prepared. The stirrer speed was maintained at $1000 \mathrm{rpm}$. All kinetic experiments were conducted for $1 \mathrm{hr}$ and repeated twice. Equilibrium adsorption studies of $\mathrm{NR}$ were undertaken at $30^{\circ} \mathrm{C}$ and $\mathrm{pH}=4$ over all carbons investigated. An equilibrium time of $24 \mathrm{hr}$ was allowed to ensure the attainment of equilibrium conditions. The residual dye concentration was determined using a UV -Vis spectrophotometer (Shimadzu Model PC-2401) with $1.0 \mathrm{~cm}$ length -path cell. Absorbance measurements, of the property diluted filtrates, were made at the maximum wavelength of $530 \mathrm{~nm}$.

\section{$\underline{\text { Results and Discussion }}$}

\section{Elemental analysis}

Table 1 comprises the elemental analysis of the investigated carbons. Results in the table depicts that the starting colloidal carbon (C) has a small oxygen content $(0.98 \%$ wt) confirming the presence of a small number of oxygen - containing groups on its surface, whereas the oxidized and urea treated carbon have much higher amounts of oxygen, i.e. 10.7, 21.8 and $7.79 \%$ for C-Th, C-N and C-u ,respectively. Thus oxidation with nitric acid slightly increased the nitrogen content; whereas treatment with urea produced a large increase in the nitrogen content [11-15]. Nitrogen may react with oxygen-containing surface groups and or with the mineral admixtures contained in the oxidized carbon with nitric acid $[18,19]$.

Oxidation of colloidal carbon was found to be associated with a decrease in the ash content.This decrease is more pronounced in case of oxidation with nitric acid which is more likely associated with a reaction of this acid with some inorganic constituents. Most of these ashes are silica and silicate compounds and other elements oxides present in the rice straw such as $\mathrm{K}_{2} \mathrm{O}, \mathrm{CaO}$, and $\mathrm{MgO}$ as reported in the literature [20].

\section{Textural properties}

The representative adsorption/desorption isotherms of nitrogen onto $\mathrm{C}, \mathrm{C}-\mathrm{N}$ and $\mathrm{C}-\mathrm{u}$, at $-196^{\circ} \mathrm{C}$, are shown in Fig. 1. The nitrogen adsorption isotherms of all investigated carbons belong to type IV of IUPAC classification. The $\mathrm{N}_{2}$ adsorption results were carefully analyzed using the conventional BET method and the t- method [16] to determine the specific surface area, the total pore volume, the mean pore radius and the volumes of micro- and non-micropores. Table 2 lists the textural properties of the prepared carbons and reveals the following results;(i) After thermally oxidizing treatment at $600^{\circ} \mathrm{C}$, the surface area, total pore volume, mean pore radius and non micropore volume increased to different degrees, for example, the non micropore volume increased about 70 $\%$, while the increase in $\mathrm{r}_{\mathrm{m}}$ value of C-Th was calculated to be $2 \%$. (ii) The surface area decreased while total pore volume and mean pore radius increased upon oxidation with concentrated nitric acid,where about $18 \%$ increase in the mean pore radius was obtained. Thus concentrated nitric acid treatment may induce destruction of the carbon texture. The non-micropore volume $\left(\mathrm{V}_{\text {non-mic }}, \mathrm{ml} / \mathrm{g}\right)$ of sample C-N represents $92.5 \%$ of its total pore volume $\left(\mathrm{V}_{\mathrm{T}}, \mathrm{ml} / \mathrm{g}\right)$. The decrease in the surface area was associated with about $23.7 \%$ increase in the mean pore radius. (iii)The treatment of carbon with concentrated urea and then heated at $400^{\circ} \mathrm{C}(\mathrm{C}-\mathrm{u})$, severely affected the porosity of carbon, where the total surface area and total pore volume increased about $3.2 \%$ and $17.6 \%$, respectively. The volume of non-micropore (i.e. mesopores) decreased about $9 \%$ than the original carbon and accompanied with a large increase in the micropore volume. Urea treatment carbon, a number of complex reactions taking place between the carbon and the urea involves a number of complex reactions under heat treatment $[19,21]$.The textural changes depend among other factors on the oxidizing agent or post treatment used. It was reported that the liquid phase oxidation does not notably change the texture of the activated carbon $[3,11,22]$. However, under more harsh conditions (concentrated acid, heating until complete evaporation) a decrease in surface area and micropore volume was observed while the non-micropore volume increased owing to the collapse of the pore walls [22].

\section{Chemistry of the carbon surface}

The chemistry of the carbon surface is attributable to the presence of the carbon - oxygen functional groups of basic or acidic character. The 
TABLE 1. Elemental analysis of the investigated carbons.

\begin{tabular}{ccccccc}
\hline Carbon & \multicolumn{7}{c}{ Elements-(\%) } \\
\hline & $\mathbf{C}$ & $\mathbf{H}$ & $\mathbf{N}$ & $\mathbf{S}$ & $\mathbf{O}$ * & Ash\% \\
$\mathbf{C}$ & 83.2 & 0.50 & 0.37 & 0.65 & 5.21 & 4.6 \\
$\mathbf{C - T h}$ & 80.18 & 0.94 & 0.74 & 0.52 & 10.70 & 4.0 \\
C-N & 73.89 & 0.91 & 1.05 & 0.47 & 21.79 & 2.7 \\
C-u & 79.45 & 0.89 & 6.30 & 0.48 & 7.78 & 4.3 \\
\hline
\end{tabular}

*obtained by the difference between the percentage content

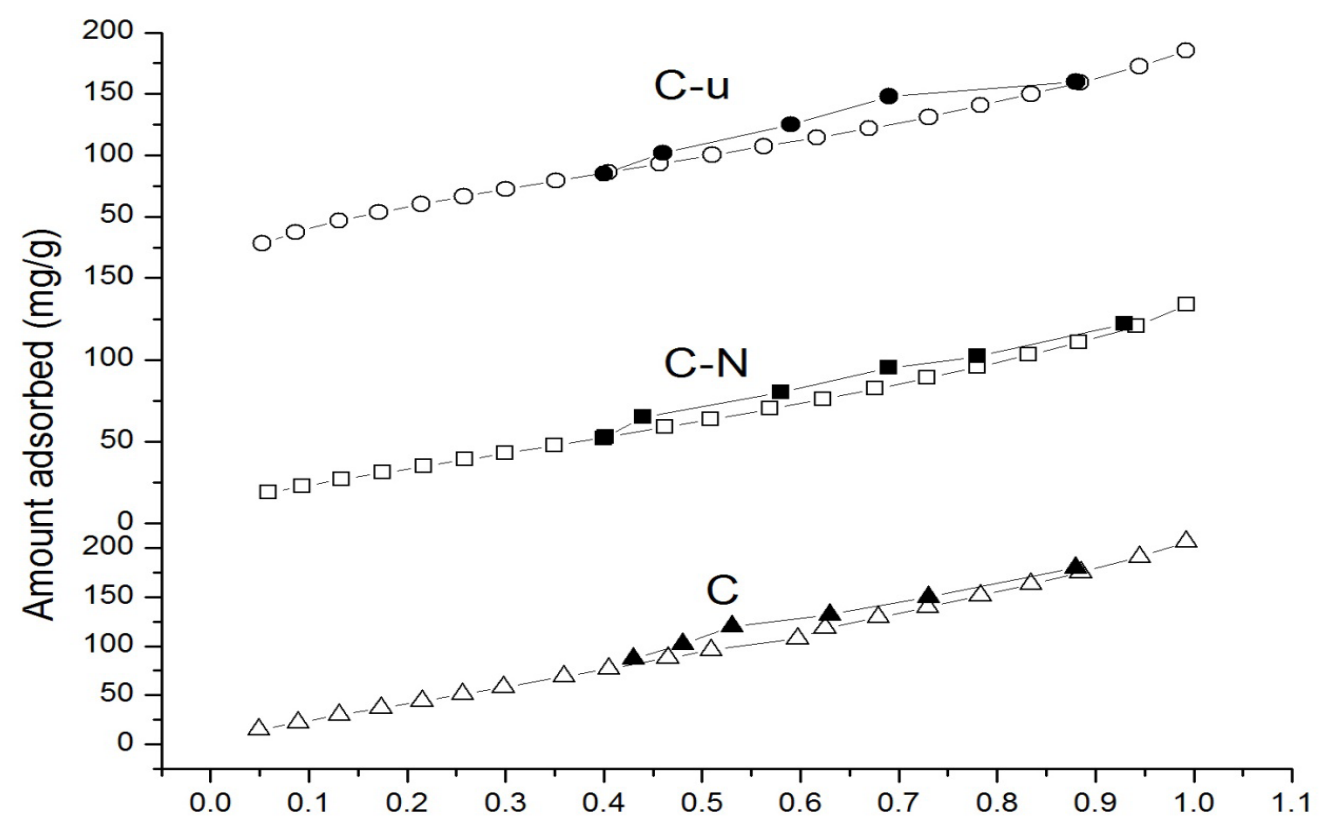

Fig. 1. Nitrogen adsorption / desorption isotherms for $\mathrm{C}, \mathrm{C}-\mathrm{N}$ and $\mathrm{C}-\mathrm{u}$.

$\mathrm{pH}$ of the aqueous slurry of a carbon affords a suited indicator on the acidity of this carbon. The functional groups on the surface of investigated carbons (C, C-Th, C-Nand C-u) were determined by Boehm'stitrations and their results are listed in Table 3 together with the surface $\mathrm{pH}$. Urea treatment resulted in sample (C-u) with weak acidic characters owing to the presence of carbonyl groups.However, the Boehm's titration was not employed in this sample as nitrogen containing groups may behave as acids in water solutions. Table 3 reveals that the surface $\mathrm{pH}$ of the colloidal carbon $\mathrm{C}$ isa basic whereas those of its oxidized derivatives are acidic. However, surface acidic and basic functional groups are existing in all the investigated carbons; the concentration of the acidic groups in the surface of carbon (C) is very low. The increase in the concentration of these acidic groups is observed during treatment of this carbon with oxidizing agents. Thus oxidation with nitric acid brought about 1.75 fold increaseswhereas about 1.41 fold increases for oxygen thermally treated rice straw at $600^{\circ} \mathrm{C}$ (C-Th). The surface $\mathrm{PH}$ of the all investigated carbons was examined for oxidation resulted in a decrease in the surface $\mathrm{pH}$ due to deposited oxygen functional groups [18]. Oxidation led to the development of new functional groups, such as carboxylic acid, lactones and anhydride,carbonyl and phenol groups. The treatment with contracted urea resulted in $\mathrm{pH}$ increase. Urea treatment increased the basic character of the modified carbon, in comparison with the colloidal carbon[4]. This increase in surface basicity may partly due to formation of nitrogen - containing groups which are able to bind with protons. Nevertheless, it can also be connected with decomposition of some oxygen - containing acidic groups that can shadow the $\pi$ electrons of graphene layer $[13,15]$.

Figure 2 shows the FTIR spectra for the 
colloidal carbon in comparison with the (a) after dry oxidation treatment, (b) after treatment with nitric acid and saturated urea in order to identify the oxygen functional groups on their surfaces. Normally, the band recorded at $3640-3410 \mathrm{~cm}^{-1}$ represents the $-\mathrm{OH}$ stretching of polymeric compounds. The band of $3000-2800 \mathrm{~cm}^{-1}$ is ascribed to the stretching vibration of $\mathrm{C}-\mathrm{H}$.The band obtained at $1740-1725 \mathrm{~cm}^{-1}$ donates the stretching vibration of $\mathrm{COO}-$ and $\mathrm{C}=\mathrm{O}$. The bands at 1324,1376 and $1000 \mathrm{~cm}^{-1}$ are assigned to the carboxyl, carbonate or carboxylic salt and metal carbonate, respectively. For oxidation thermally at $600{ }^{\circ} \mathrm{C}$ for $4 \mathrm{hr}$ in absence of any active agents may be leaving a less contaminated surface (tarry materials and hydrocarbons) ready to interact with the residual and combined oxygen $[2,4,15$, $19]$, thus creating oxygen $\mathrm{C}=\mathrm{O}$ groups either of acidic or basic groups type [2]. Nitric acid is a good oxidizing agent for the conversion of basic groups. It was indicated that the increase in the intensities of the bands at 1625, 1390 and 3425 $\mathrm{cm}^{-1}$ after the nitric acid treatment can increase the binding capability of carbon used. Figure $2 \mathrm{~b}$ also shows that the same peaks appeared after carbon modified with concentrated urea and heated at $450{ }^{\circ} \mathrm{C}$ for $1 \mathrm{hr}$. Clear bands were seen that they could be related to nitrogen - containing species. For the $\mathrm{C}-\mathrm{u}$ carbon, the presence of both $\mathrm{N}-\mathrm{H}$ at $\left(1412 \mathrm{~cm}^{-1}\right)$ and $\mathrm{C}-\mathrm{N}$ at $\left(1078 \mathrm{~cm}^{-1}\right)$ bands might indicate the formation of amide and amine groups [15]. Therefore, the resulting modified carbon $\mathrm{C}$-u contains to some extent oxygen containing groups with a basic nature, however; it is still acidic in character.

Effect of $\mathrm{pH}$ and temperature on adsorption

Among the factors affecting the adsorption of an adsorbate from its aqueous solution, the $\mathrm{pH}$, temperature, initial concentration and equilibrium time are of great significance. Preliminary experiments have been performed for the determination of the appropriate $\mathrm{pH}$ which leads to maximum NR dye adsorption. Figure 3 shows the effect of $\mathrm{pH}$ on adsorption of NR dye by different carbon samples. Obviously, when all other adsorption conditions are the same apart from the solution $\mathrm{pH}$, the maximum NR dye adsorption from solution was occurred at $\mathrm{pH}=4$. This trend was true for all the investigated carbons. Adsorption kinetic and isotherms of NR dye were undertaken at $\mathrm{pH}=4$.

The effect of adsorption temperature may be indicated by comparing the capacity of colloidal carbon (C) at different temperatures of $30-50^{\circ} \mathrm{C}$ (figure not shown here). This carbon shows increase of about $21.6 \%$ in the adsorption capacity upon rising the adsorption temperature from 30 to $40^{\circ} \mathrm{C}$. Moreover, about $37.3 \%$ increase upon further rise in the adsorption temperature from 40 to $50^{\circ} \mathrm{C}$. The increase in temperature can lead to higher diffusion rates accompanied by decreasing viscosity and density of the solute, enhancing the extent of adsorption [23]. The recorded increase in magnitude of the equilibrium adsorption with increasing temperature also indicated that the adsorption of NR dye onto colloidal carbon $\mathrm{C}$ was endothermic in nature.

\section{Adsorption kinetics \\ Effect of initial concentration on NR dye}

Figure 4 shows the extent of NR dye adsorption onto colloidal carbon $(\mathrm{C})$ as a function

TABLE 2.Textural properties of the investigated carbons obtained from nitrogen adsorption -desorption at $-196^{\circ} \mathrm{C}$.

\begin{tabular}{|c|c|c|c|c|c|}
\hline Sample & $\begin{array}{l}S_{\text {BET }} \\
\mathrm{m}^{2} / \mathrm{g}\end{array}$ & $\begin{array}{c}\mathrm{V}_{\mathrm{T}} \\
\mathrm{ml} / \mathrm{g}\end{array}$ & $\begin{array}{c}\bar{r} \\
\mathbf{n m}\end{array}$ & $\begin{array}{l}\mathbf{V}_{\text {micro }} \\
\mathbf{m l} / \mathbf{g}\end{array}$ & $\begin{array}{c}V_{\text {non-micro }} \\
\mathrm{ml} / \mathrm{g}\end{array}$ \\
\hline $\mathrm{C}$ & 256 & 0.1861 & 1.39 & 0.007 & 0.1791 \\
\hline C-Th & 265 & 0.2111 & 1.42 & 0.004 & 0.2041 \\
\hline $\mathrm{C}-\mathrm{N}$ & 153 & 0.2291 & 1.72 & 0.017 & 0.2121 \\
\hline C-u & 265 & 0.2198 & 1.74 & 0.057 & 0.1620 \\
\hline
\end{tabular}

TABLE 3. Surface functional groups (meq/g) and the $\mathrm{pH}$ of the investigated carbons.

\begin{tabular}{llllll}
\hline Carbons & Carboxylic & Lactonic & Phenolic & Carbonyl & Surface pH \\
\hline C & 0.06 & 0.09 & 0.01 & 0.20 & 7.9 \\
C-Th & 0.54 & 0.42 & 0.55 & 0.67 & 6.7 \\
C-N & 0.83 & 0.40 & 0.50 & 0.91 & 4.0 \\
C-u & - & & - & - & \\
\hline
\end{tabular}


(a)
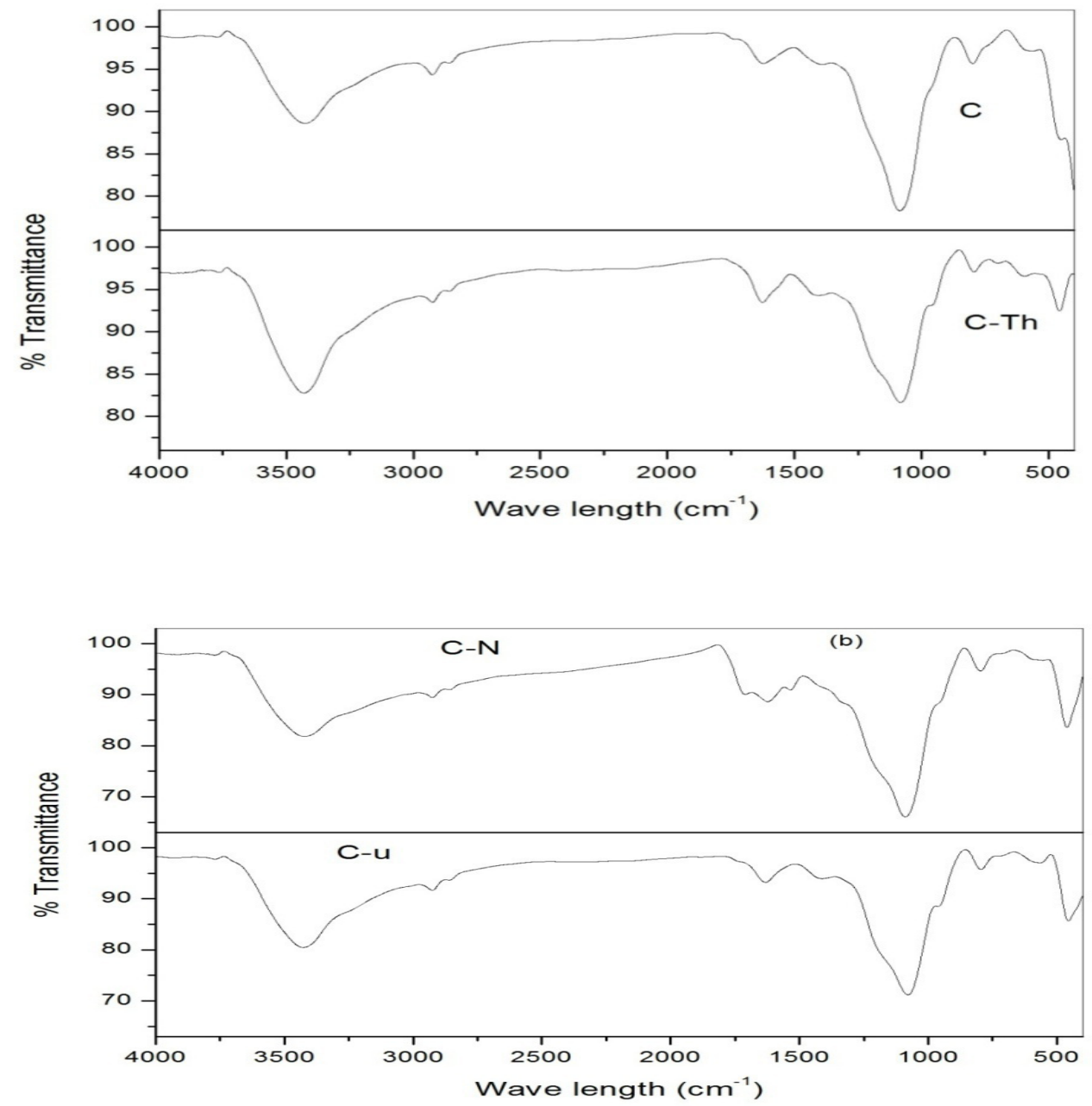

Fig. 2. Representative FTIR patterns. (a) Samples C and C-Th (b) samples C-N,C-u.

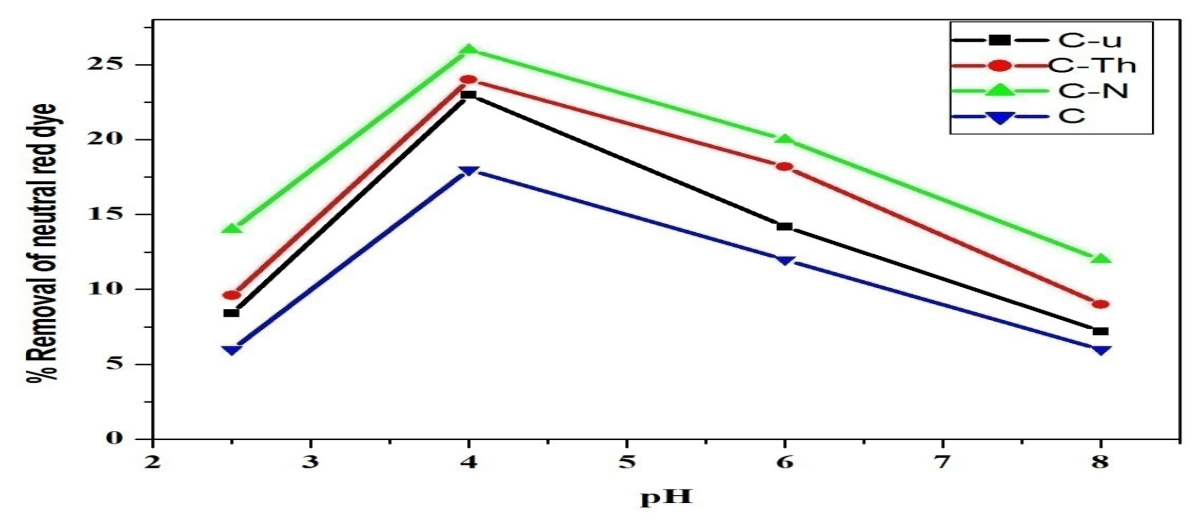

Fig. 3. Effect of pH on the adsorption of NR dye over all investigated samples 


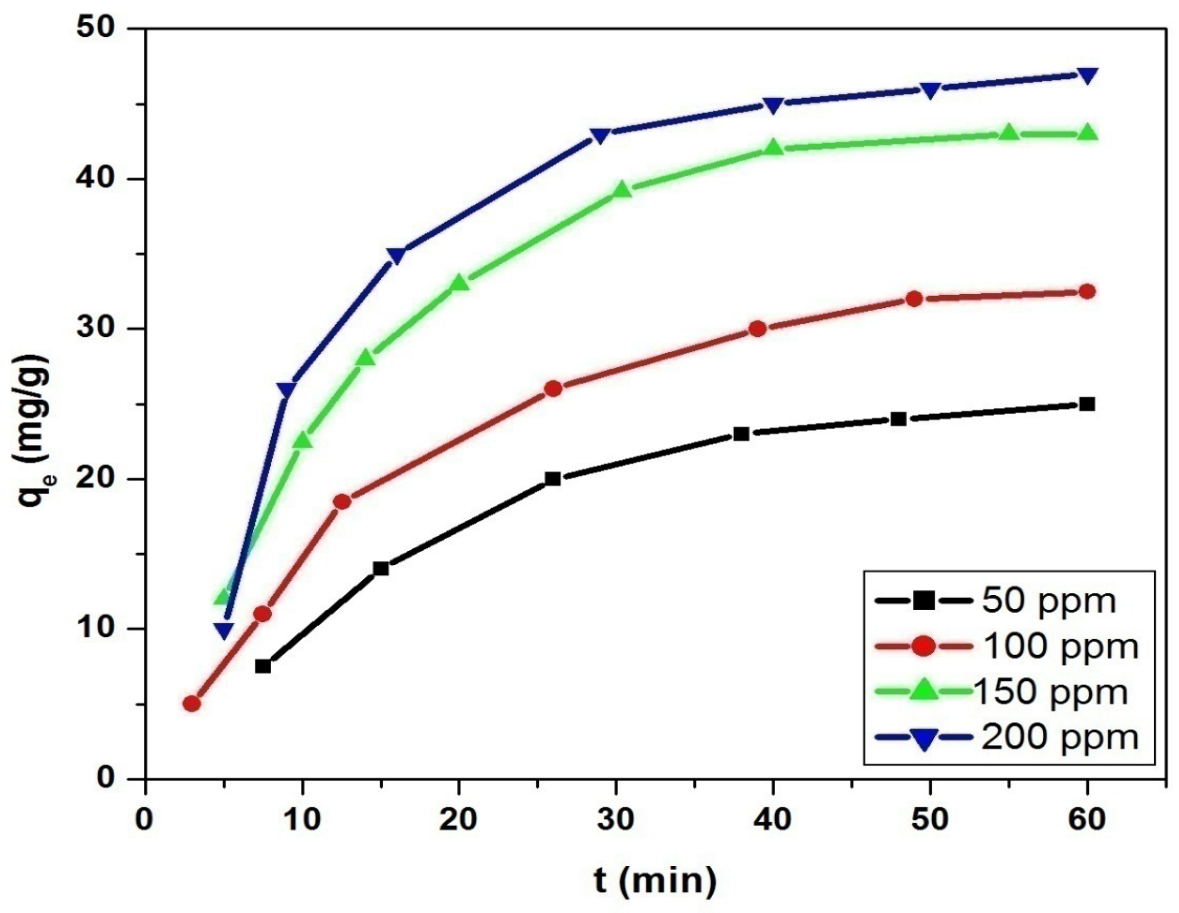

Fig.4. The extent of NR dye adsorption of colloidal carbon (C) as a function of time and initial concentration.

of time and initial concentration. The quantity of NR adsorbed per unit mass increased from 20 to $39 \mathrm{mg} / \mathrm{g}$ as the NR concentrationincreased from 50 to $200 \mathrm{mg} / \mathrm{L}$. The equilibrium was attained at $40 \mathrm{~min}$ for all the initial concentration studied indicating completely monolayer adsorption. Thesurface of colloidal carbon contains a number of active sites and the solute (NR) uptake can be correlated to the active sites on equilibrium time. Furthermore, up to $95 \%$ of total amount of dye uptake was found to occur in the first rapid phase (40min) and then the adsorption rate was found to decrease. The increase in adsorbed amount with an increase in initial concentration is attributable to the increase in the mass transfer driving force. From the above mentioned discussion, the surface of colloidal carbon contains a large number of acidic sites.

The kinetic models used in order to investigate the mechanism of adsorption were the pseudo first order (Eq.(1) and pseudo second order kinetic model (Eq. (2) and the intra-particle diffusion model (Eq. (3). The adsorption of NR onto the investigated carbons $\mathrm{C}, \mathrm{C}-\mathrm{Th}, \mathrm{C}-\mathrm{N}$ and $\mathrm{C}-\mathrm{u}$ with an initial concentration $200 \mathrm{mg} / \mathrm{L}$ and temperature $30^{\circ} \mathrm{C}$ were examined.

$$
\begin{aligned}
& \log \left(q_{e}-q_{t}\right)=\log q_{e}-\frac{k_{t} t}{2.303} \\
& \frac{t}{q_{t}}=\frac{1}{k_{2} q_{e}^{2}}+\frac{t}{q_{e}}
\end{aligned}
$$

where $\mathrm{q}_{\mathrm{e}}$ and $\mathrm{q}_{\mathrm{t}}$ are the adsorbed amounts of NR dye at equilibrium and at time $\mathrm{t}(\mathrm{mg} / \mathrm{g})$, respectively. $\mathrm{k}_{1}$ is the pseudo-first order adsorption rate constant $\left(\mathrm{min}^{-1}\right)$, and $\mathrm{k}_{2}$ is the pseudo-second order adsorption rate constant (g/mg.min).

If intra-particle diffusion is assumed to be the rate -limiting step in the adsorption process, the equivalent equation may be written as the equation of Weber and Morris.

$$
\mathrm{q}_{\mathrm{t}=} \mathrm{k}_{\mathrm{id}} \mathrm{t}^{0.5}+\mathrm{C}
$$

where $\mathrm{k}_{\mathrm{id}}$ is the intra-particle diffusion constant $\left(\mathrm{mg} / \mathrm{g} \cdot \mathrm{min}^{0.5}\right)$ and $\mathrm{C}$ is constant.

The adsorption kinetic curves of the NR dye adsorption onto all investigated carbons are shown in Fig. 5. The kinetic parameters evolving from the application of the three models are given in Table 4. 
The first order kinetic equation was applied to the obtained data; adequate straight lines were obtained with high values of correlation $\mathrm{R}^{2}$ (Table 4). For the pseudo - first order equation is shown in Fig 6 . The correlation coefficient $\left(R^{2}\right)$ values are presented in Table 4 which approached unity and indicate the applicability of the pseudo first-order kinetic model for NR adsorption onto all investigated carbons. It is obvious from Table 4 that the adsorption capacity $\mathrm{q}_{\mathrm{e}}$ at equilibrium very close to the experimental $\mathrm{q}_{\mathrm{e}}(\exp )$. On the other hand, by examining the pseudo-second order kinetic model, the data of the experimental values of $\mathrm{q}_{\mathrm{e}}(\exp )$ were not consistent with the calculated ones. Also, the values of correlation coefficients $\mathrm{R}^{2}$ of the adsorption of NR dye onto all investigated carbons are approaching unity as listed in Table 4. This suggests the postulation that the adsorption of NR on the studied carbons followed pseudo- first order kinetics.

In order to predict the rate limiting step intraparticle diffusion applied through the use of Eq. (3). Figure 7 shows that the lines do not pass through the origin. For intra-particle diffusion is not the only rate limiting step indicating the effect of film diffusion (boundary layer diffusion). As seen in Fig 7, all the plots show a linear portion extending up wards to a curved plateau. The initial line section represents the surface or film diffusion and the second one is the intraparticle or pore diffusion. Thus the adsorption process of NR is controlled by both film and pore diffusions, respectively. The values of $\mathrm{k}_{\mathrm{id}}$ and $\mathrm{C}$ were estimated and given in Table 4.

The intra-particle diffusion constant $\mathrm{k}_{\mathrm{id}}$ also exhibits a significant rise with the increase in the acidity (number of acidic sites) of sorbent which is in agreement with the surface $\mathrm{pH}$ values of the investigated carbons. The $\mathrm{k}_{\mathrm{id}}$ value increases in the order 8.79>8.20>7.89>6.31 for C-N,C-u, C-Th and $\mathrm{C}$, respectively. These indicate that modification of colloidal carbon $\mathrm{C}$ with concentrated nitric acid to give $\mathrm{C}-\mathrm{N}$ resulted in a considerable increase in $\mathrm{k}_{\mathrm{id}}$, i.e. a nearly 1.4 fold increase. While modification of $\mathrm{C}$ with concentrated urea and then heated at $450{ }^{\circ} \mathrm{C}$ is associated with nearly 1.3 fold increase in the value of $\mathrm{k}_{\mathrm{id}}$. It seems that modification of colloidal carbon with concentrated nitric acid or with saturated urea then heated at $450^{\circ} \mathrm{C}$ for $1 \mathrm{hr}$ resulted in generally the same increase in $\mathrm{k}_{\mathrm{id}}$.

\section{Equilibrium adsorption}

In this investigation the adsorption of NR was carried out over a wide range of equilibrium concentration and $\mathrm{pH}=4$. The adsorption isotherms of NR are shown in Fig. 8. The isotherms are of L- type according to Gile's classification. Three models namely, Langmuir, Freundlich and Dubinin-Radushkevich(D-R), were applied for the equilibrium data of NR. The isotherms are similar to those characterizing the adsorption but with the steep initial portions and with slight tendency to attain constant adsorption value. The Langmuir adsorption model suggests that adsorption takes place at specific, homogeneous adsorption sites within the adsorbent, and that intermolecular forces lessen rapidly with the distance from the adsorption surface and these isotherms are obey Langmuir's equation's.

$$
C_{t} / q_{t}=\frac{1}{K_{t} Q_{o}}+\frac{1}{Q_{o}} C_{t}
$$

where $\mathrm{C}_{\mathrm{e}}$ is the equilibrium concentration (mg/ $\mathrm{L}), \mathrm{Q}_{\mathrm{o}}$ the monolayer capacity $(\mathrm{mg} / \mathrm{g})$ and $\mathrm{K}_{\mathrm{L}}$ is the adsorption equilibrium constant $(\mathrm{L} / \mathrm{mg})$.

The linear Langmuir plots are shown in Fig. 9 and the equilibrium sorption data are listed in Table 5. To estimate the best adsorption isotherm model, the correlation coefficient values $\left(\mathrm{R}^{2}\right)$ were calculated and listed in Tables 5 and 6.

Freundlich isotherm model is an empirical equation that can describe the reversible adsorption onto heterogeneous surface at sites with different energy of adsorption and is not restricted to the formation of the monolayer of adsorbate. The linear form of this model is expressed as:

$$
\log q_{\mathrm{s}}=\log K_{F}+\frac{1}{n} \log C_{\mathrm{s}}
$$

where $K_{F}$ is the Freundlich constant $(\mathrm{mg} / \mathrm{g}) /(\mathrm{L} /$ $\mathrm{mg})^{1 / \mathrm{n}}$, and also referred to adsorption capacity, while $n$ is the heterogeneity factor and related to adsorption intensity. The value of $n$ can be used also to describe the adsorption whether is linear $(n=1)$ or a physical process $(n>1)$ is favorable, or a chemical process $(n<1)$. The values of $K_{F}$ and $n$ are determined from the intercept and slope of the plot $\log q_{e}$ versus $\log C_{e}$, respectively, and are listed in Table 5.

Another model was also employed to the equilibrium adsorption data of NR dye onto all investigated carbons. This model adopted by Dubinin-Radushkevich (D-R) model (6). It supposes that only a small fraction of the surface is uniform in structure and energetically homogenous. The D-R equation is as the following:

$$
\mathrm{q}_{2}=\mathrm{q}_{\mathrm{n}} e^{-\beta \xi^{2}}
$$

where $\mathrm{q}_{\mathrm{e}}$ is the amount adsorbed substances at the equilibrium concentration $\mathrm{C}_{\mathrm{e}}, \mathrm{q}_{\mathrm{m}}$ is the maximum amount adsorbed and it is also known as the adsorption capacity, $\beta$ is a constant correlated 


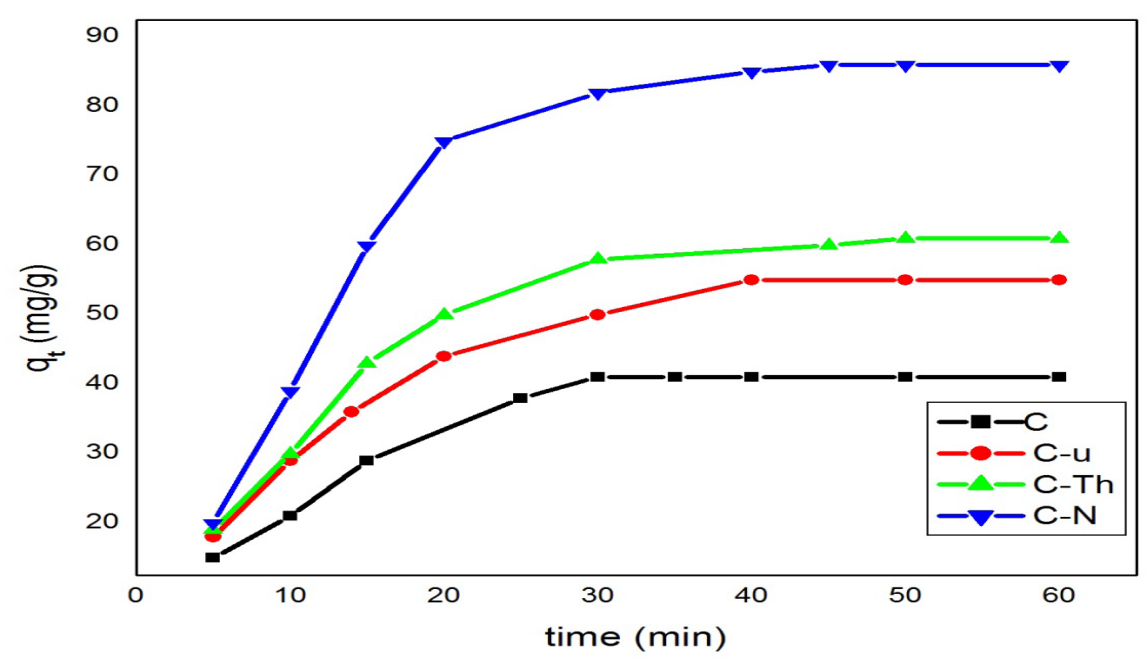

Fig. 5. Kinetic curves of dye sorption onto Carbons investigated at $30^{\circ} \mathrm{C}$.

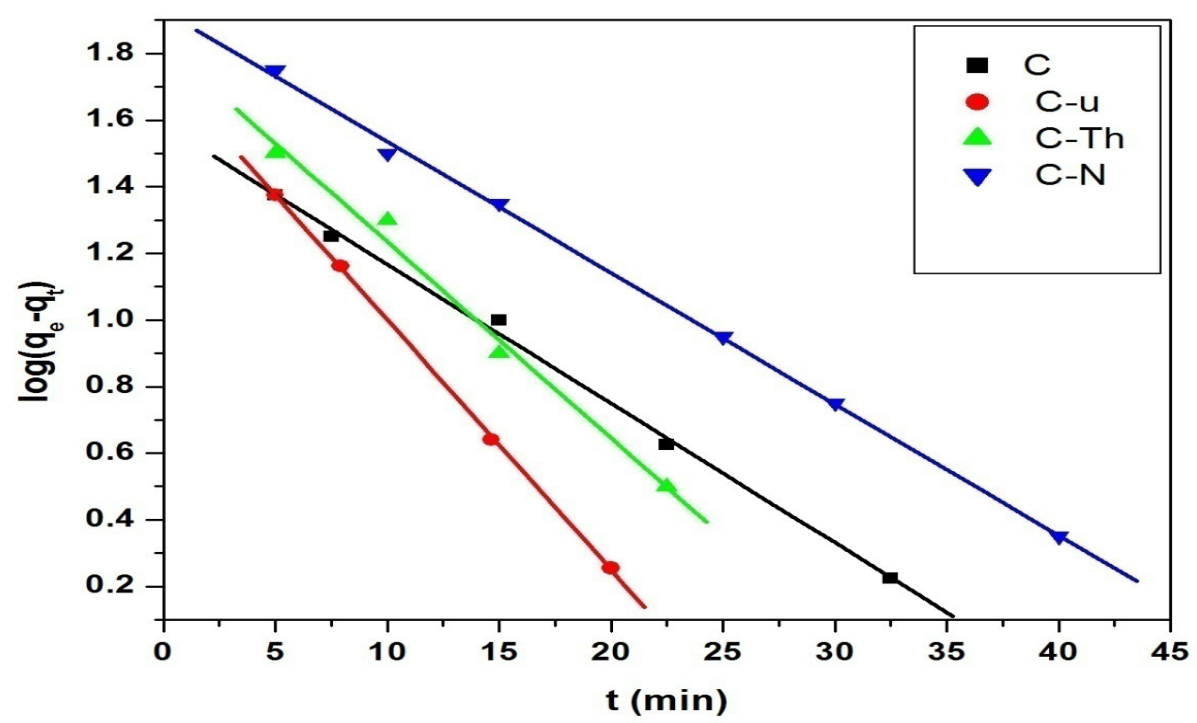

Fig. 6. Linear plots of kinetic first - order of NR dye sorption onto Carbons investigated at $30^{\circ} \mathrm{C}$.

to the energy and $\xi$ the potential energy of the surface which equal RTLn $\left(1+1 / \mathrm{C}_{\mathrm{e}}\right)$ where $\mathrm{R}$ is the gas constant $(\mathrm{kJ} / \mathrm{mol} . \mathrm{K}), \mathrm{T}$ is the absolute temperature. The $\mathrm{D}-\mathrm{R}$ equation can be written as:

$$
\text { Ln } q_{1}=L_{n} q_{m}-\beta z^{2}
$$

A plot of $\mathrm{Lnq}_{\mathrm{e}}$ versus $\xi^{2}$ gave a straight line (not shownhere). The values of $\mathrm{q}_{\mathrm{m}}$ and $\beta$ were obtained are shown in Table 6.The intercept and slope of the straight lines obtained from the relationship:

$$
\mathrm{E}_{\mathrm{a}}=1 / 2(-\beta)^{0.5}
$$

The values of $\mathrm{E}_{\mathrm{a}}$ obtained were between 0.0318 and $0.0485 \mathrm{KJ} / \mathrm{mol}$ the value of $\mathrm{E}$ signifies that the adsorption of NR dye onto all carbons investigated is physical forces,i.e. dispersion or Van der Waals forces. The Langmuir and D-R models exhibit higher values of $\mathrm{R}^{2}(>0.99)$ than that obtained from Freundlich model. Thus the adsorption of NR dye onto the prepared adsorbents is well fitted to Langmuir and D-R models. 


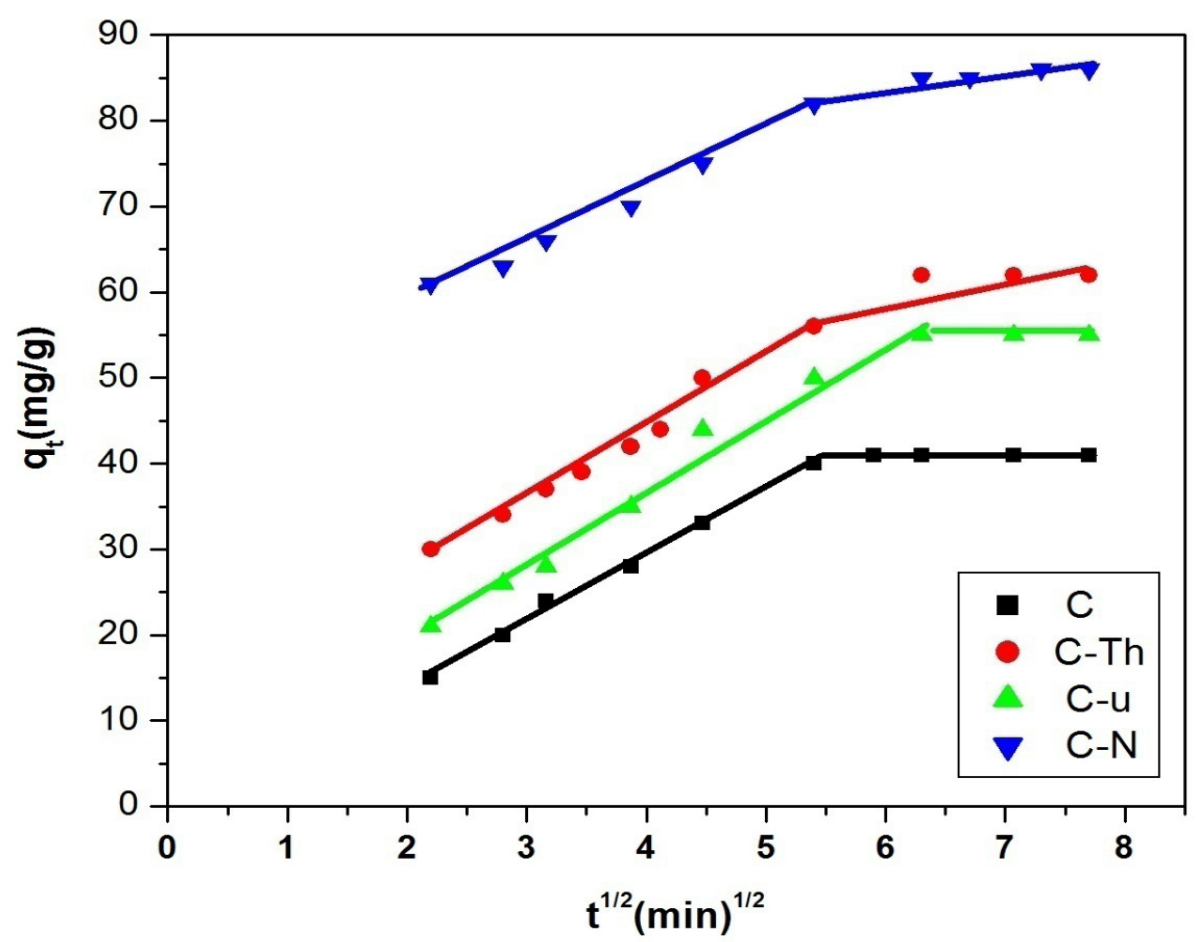

Fig. 7. Intraparticle diffusion plots for the adsorption of NR onto Carbons investigated at $30^{\circ} \mathrm{C}$.

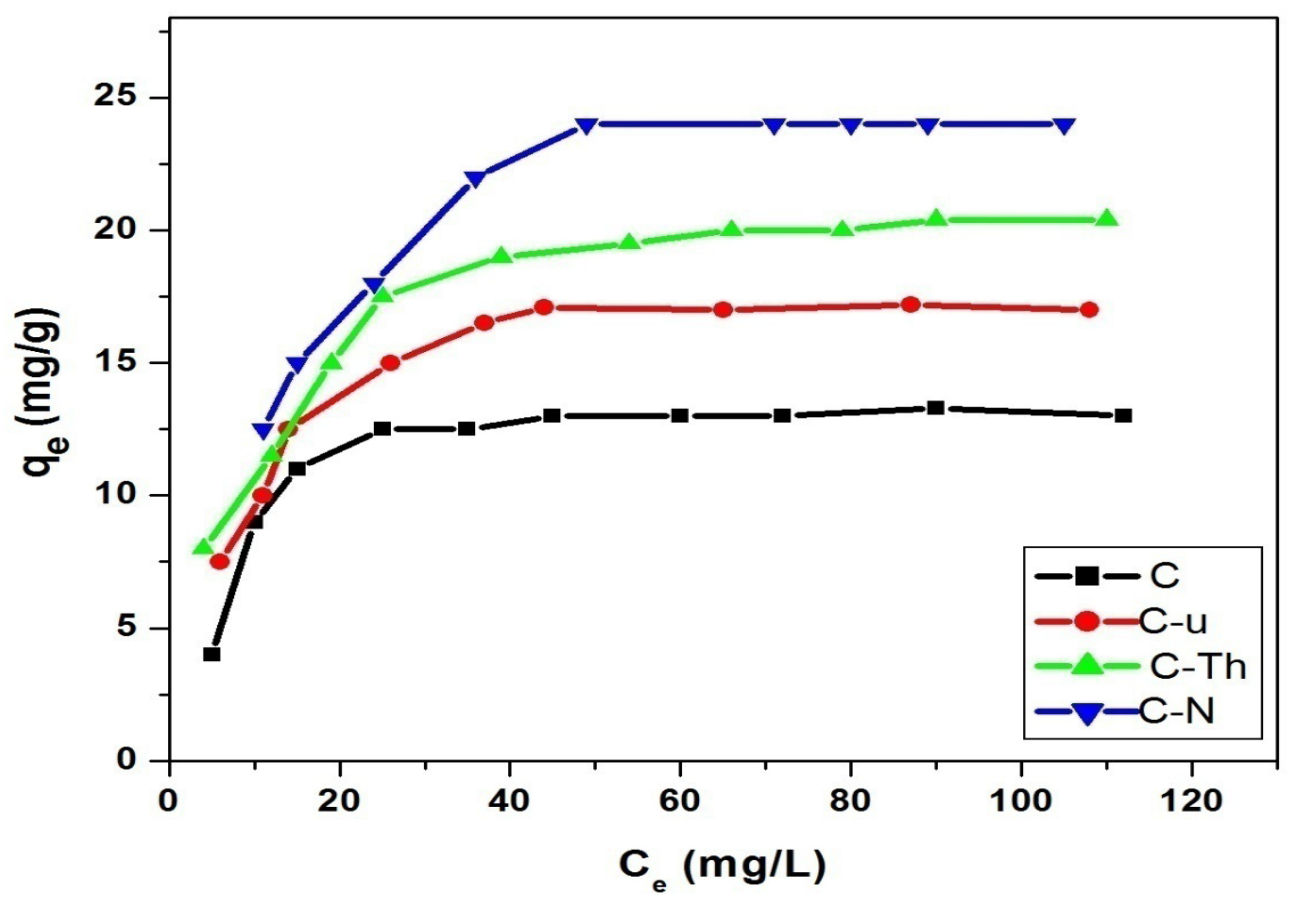

Fig. 8. Equilibrium adsorption isotherms of dye onto investigated carbons at $30^{\circ} \mathrm{C}$ and $\mathrm{pH}=4$. 


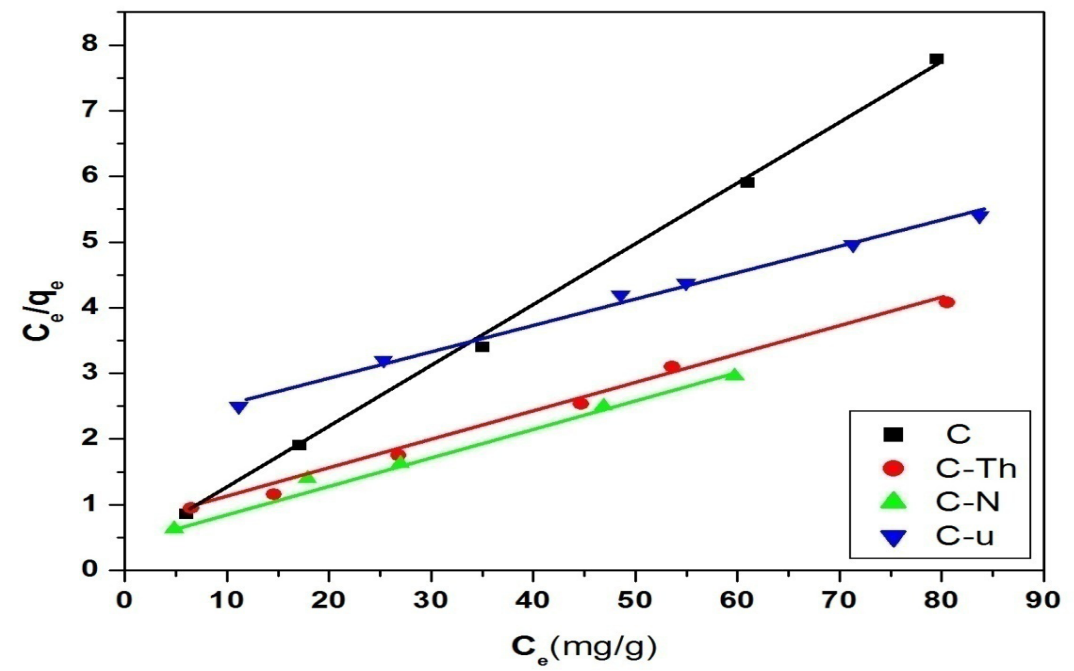

Fig. 9. Representative Langmuir of the adsorption of NR dye onto investigated Carbons.

TABLE 4. Kinetic parameters for the adsorption of NR dye onto investigated carbons.

\begin{tabular}{cccccccccc}
\hline Adsorbents & \multicolumn{3}{c}{ Pseudo-first -order } & \multicolumn{3}{c}{ Pseudo-second-order } & & Intraparticle diffusion \\
\hline & $q_{e}($ exp $)$ & $k_{1}$ & $q_{e 1}$ & $R^{2}$ & $k_{2}$ & $q_{e 2}$ & $R^{2}$ & $k_{i d}$ & $C$ \\
C & 39 & 0.0114 & 42.2 & 0.998 & $1.024 \times 10^{-3}$ & 62.5 & 0.993 & 6.31 & 2 \\
C-Th & 51.1 & 0.36 & 56.1 & 0.994 & $7.8 \times 10^{-4}$ & 80 & 0.996 & 7.89 & 12 \\
C-N & 75.3 & 0.61 & 79.3 & 0.997 & $4.9 \times 10^{-4}$ & 125 & 0.974 & 8.79 & 46.2 \\
C-u & 46.0 & 0.49 & 50.2 & 0.998 & $6.5 \times 10^{-4}$ & 83.3 & 0.997 & 8.20 & 4 \\
\hline
\end{tabular}

TABLE 5. Langmuir and Freundlich equation coefficients for NR dye adsorption onto investigated carbon.

\begin{tabular}{|c|c|c|c|c|c|c|}
\hline Adsorbents & \multicolumn{3}{|c|}{ Langmuir parameters } & \multicolumn{3}{c|}{ Freundlich parameters } \\
\hline & $\boldsymbol{K}_{\boldsymbol{L}}$ & $\boldsymbol{Q}_{o}$ & $\boldsymbol{R}^{2}$ & $\boldsymbol{K}_{\boldsymbol{F}}$ & $\boldsymbol{n}$ & $\boldsymbol{R}^{2}$ \\
\hline $\mathbf{C}$ & 0.285 & 10 & 0.996 & 4.79 & 4.0 & 0.956 \\
\hline C-Th & 0.057 & 25 & 0.997 & 3.16 & 2.27 & 0.975 \\
\hline C-N & 0.64 & 24.2 & 0.981 & 3.47 & 2.5 & 0.963 \\
\hline C-u & 0.022 & 22.5 & 0.997 & 3.39 & 1.5 & 0.988 \\
\hline
\end{tabular}

TABLE 6. D-R isotherm constants

\begin{tabular}{ccccc}
\hline Adsorbents & $\begin{array}{c}\mathbf{E}_{\mathbf{a}} \\
(\mathbf{k J} / \mathbf{m o l})\end{array}$ & $\begin{array}{c}\mathbf{q}_{\mathbf{m}} \\
(\mathbf{m m o l} / \mathbf{g})\end{array}$ & $\begin{array}{c}\boldsymbol{\beta} \times \mathbf{1 0}^{-3} \\
\left(\mathbf{m o l} \mathbf{2}^{\mathbf{k}} / \mathbf{L}^{2}\right)\end{array}$ & $\mathbf{R}^{\mathbf{2}}$ \\
\hline $\mathbf{C}$ & 0.046 & 0.0019 & 0.236 & 0.997 \\
$\mathbf{C - T h}$ & 0.0318 & 0.0013 & 0.317 & 0.996 \\
$\mathbf{C - N}$ & 0.0485 & 0.0053 & 0.212 & 0.999 \\
$\mathbf{C - u}$ & 0.046 & 0.0015 & 0.228 & 0.998 \\
\hline
\end{tabular}




\section{Conclusion}

Colloidal carbon developed from rice straw exhibited surface area of $256 \mathrm{~m}^{2} / \mathrm{g}$ and total pore volume of $0.04861 \mathrm{ml} / \mathrm{g}$. Nevertheless, a large fraction of this area is located in range of micropore sizes. Basic properties are dominant for untreated colloidal carbon. Thermally, nitric acid, and urea modified colloidal carbons were prepared. These sorbents were characterized by determining their physical and chemical properties including $\mathrm{N}_{2}$ adsorption, elemental analysis,FTIR and surface acidity. The cationic NR dye was highly adsorbed on nitric acid - modified form, particularly at $\mathrm{pH}=4$. Oxidation of colloidal carbon with oxidizing agent thermally or acid treated was associated with a decrease of surface area and total pore volume but, with an increase in the pore dimensions. On the other hand, urea modified carbon was associated with increase of surface area and increase in the basic character. This might be partly attributed to formation of nitrogen groups. The adsorption was of the physical adsorption type and the adsorption data followed Langmuir and D-R models and followed pseudofirst -order kinetics. The equilibrium adsorption data followed Langmuir and D-R models. The mean energy $\left(\mathrm{E}_{\mathrm{a}}\right)$ obtained indicated the physical nature of sorption process. The adsorption capacities of non - modified and modified carbon toward NR dye adsorption were found to increase in the subsequent order $\mathrm{C}-\mathrm{N}>\mathrm{C}-\mathrm{Th}>\mathrm{C}-\mathrm{u}>\mathrm{C}$.

\section{References}

1. Calzado, M., Valero-Romero, MJ., Garriga, P., Chica, A., Guerrero-Pérez, M.O. and RodríguezMirasol, J., Lignocellulosic waste-derived basic solids and their catalytic applications for the transformation of biomass waste, Catal. Today $\mathbf{2 5 7}$, 229 (2015).

2.Bandosz, T. J., and Ania, C.O., Surface chemistry of activated carbons and its characterization, In: Activated Carbon Surfaces in Environmental Remediation, T.J. Bandosz (Ed.) (C) Elsevier Ltd., pp. 186-193 (2006).

3. Pereira, M. F. R., Soares, S. F., Órfão, J. J. M. and Figueiredo J. L., Adsorption of dyes on activated carbons: influence of surface chemical groups, Carbon, 41, 811 (2003).

4. El-Hendawy, A.A., Influence of $\mathrm{HNO}_{3}$ Oxidation on the Structure and Adsorptive Properties of CorncobBased Activated Carbon. Carbon, 41,713 (2003).

5. Dabrowski, A., Adsorption - from theory to practice, Advances in Colloid and Interface Sci. 93, 135 (2001).

6. Purk, S.J. and Jung, Y., Adsorption Behaviors of Chromium (III) and (VI) on Electroless Cu-Plated Activated Carbon Fibers, J.Colloid interface Sci. 243, 316 (2001).

7. Guerrero-Pérez, M.O., Valero-Romero, M.J., Hernández S., López-Nieto J.M., RodríguezMirasol, J. and Cordero, T., Lignocellulosic-derived mesoporous materials: An answer to manufacturing non-expensive catalysts useful for the biorefinery processes, Catal. Today, 195, 155 (2012).

8. Sayed, A.A.S., Khalil L. and El Nabarawy Th., Removal of Reactive Blue 19 dye from Aqueous Solution Using Natural and Modified Orange Peel, Carbon Letters, 13, 212 (2012).

9. Figueiredo, J.L. and Pereira, M.F.R., The role of surface chemistry in catalysis with carbons, Catal. Today, 150, 2 (2010).

10. Bandosz, M., Seredych,T. J., Rodríguez-Castellon, E., Cheng, Y., Daemen, L. L. and Ramírez-Cuesta, A. J., Evidence for $\mathrm{CO}_{2}$ reactive adsorption on nanoporous $\mathrm{S}$ - and N-doped carbon at ambient conditions, Carbon ,96, 856 (2016).

11. Fathy, N.A. and El-Sherif, I.Y., Equilibrium removal of $\mathrm{Pb}$ (II) ions from aqueous solution onto oxidizedKOH-activated carbons, Carbon Letters, 12, 1 (2011).

12. Biner, J., Salbut, P., Bertozecki, S., Boudou, J., Broniek, E. and Teresa, S., Modified active carbons from precursors enriched with nitrogen functions: Sulfur removal capabilities, Fuel, 77, 519 (1998).

13. Shafeeyan, M.S., Daud, W. M., Houshm A. and Shamiri, A., A review on surface modification of activated carbon for carbon dioxide adsorption, $J$. Anal. Appl. Pyrolysis, 89, 143 (2010).

14. Xu, T. and Liu, X., Peanut Shell Activated Carbon: Characterization, Surface Modification and Adsorption of $\mathrm{Pb} 2+$ from Aqueous Solution, Chinese J. Chem. Eng. 16, 401 (2008).

15. Hulicova-Jurcakova, D., Seredych, M., Lu, G.Q. and Bandosz, T.J., Combined effect of nitrogen and oxygen-containing functional groups of microporous activated carbon on its electrochemical performance in supercapacitors, Adv. Func. Materials, 19, 438 (2009).

16. Kenneth, S., The use of nitrogen adsorption for the characterization of porous materials, Colloid Surface A. 187-188, 3 (2001).

17. Boehm, H.P., Diehl, E., Heck, W. and Sappok, R., Surface oxides of carbon, Angew. Chem. Internat. 


\section{Edit. 3,669 (1964).}

18. Youssef, A. M., El-Nabarawy,Th. and El-Shafey, E. I., Modified activated carbons from olive stones for theremoval of heavy metal, Carbon Letters 7 , 1 (2006).

19. Fathy, N. A., Shouman, M. A., Aboelenin, R. M. M., Nitrogen, and phosphorous-doped porous carbon xerogels as metal-free catalysts for environmental catalytic peroxide oxidation of 4-nitrophenol, AsiaPac. J. Chem. Eng. 11, 836 (2016).

20. Lu ,P. and Hsieh, Y.-L., Highly pure amorphous silica nano-disks from rice straw, Powder Technology, 225, 149 (2012).

21. Gray, M.L., Soong, Y., Champagne, K.J.,Baltrus J., Stevens. Jr. R.W., Toochinda. P. and Chuang. S.S.C., Surface-modified spherical activated carbon materials for pre-combustion carbon dioxide capture, Sep. Purif. Technol. 35, 31 (2004).
22. Figueiredo. J.L., Pereira. M.F.R., Freitas. M.M.A. and Orfao, J.J.M., Modification of the surface chemistry of activated carbons, Carbon, 37, 1379 (1999).

23. Cheng, Z., Zhang, L., Guo, X., Jiang, X. and Li, T., Adsorption behavior of direct red 80 and congo red onto activated carbon/surfactant: Process optimization, kinetics and equilibrium, Spectrochimica Acta Part A: Molecular and Biomolecular Spectroscopy, 137, 1126 (2015).

(Received:19 / 5 / 2017 ; accepted:12 / 6/2017)

\section{إزالة الصبغ الاحمر المتعادل الكاتيونى من المحاليل المائية باستخدام قش الأرز الطبيعي والمعدل

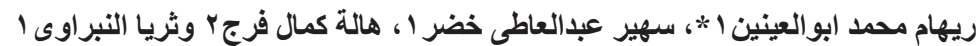

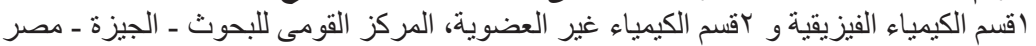

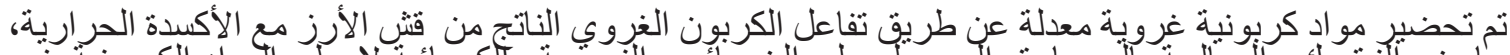

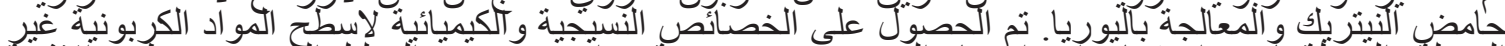

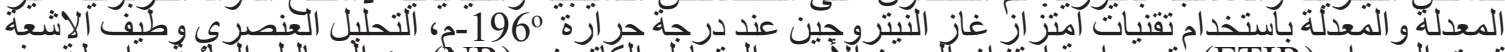

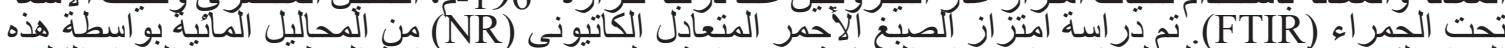

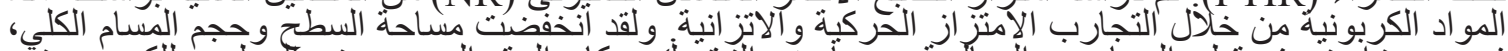

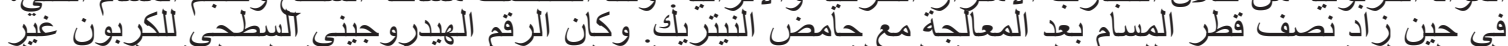

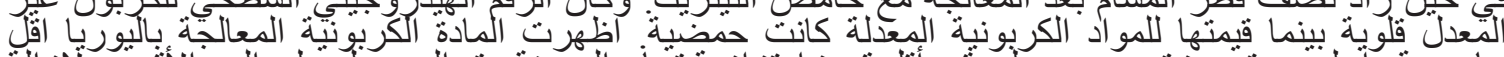

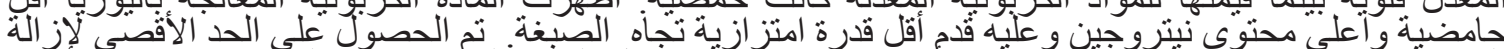

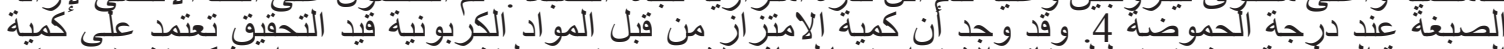

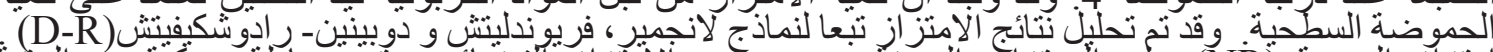

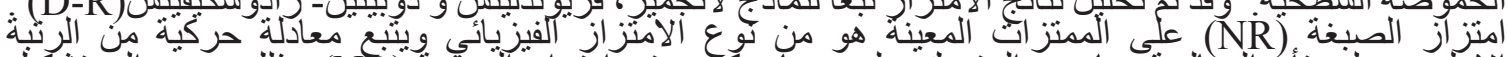

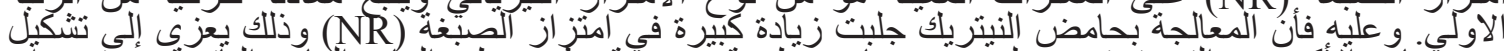

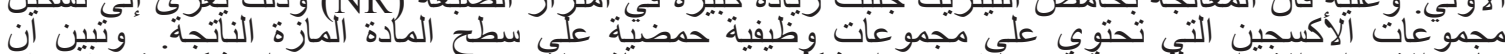

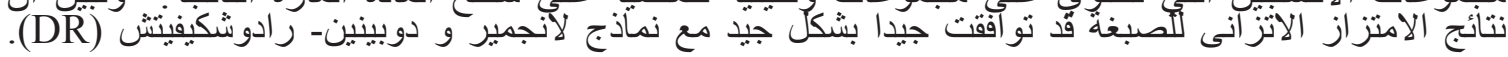


Egypt.J.Chem. 60 , No.4 (2017) 